\title{
The Hebrew Web Communicative Development Inventory (MB-CDI): Lexical Development Growth Curves
}

\author{
Hila GENDLER-SHALEV ${ }^{1 *}$ (D) and Esther DROMI ${ }^{2}$ \\ ${ }^{1}$ Communication Sciences and Disorders, University of Haifa, Israel, and ${ }^{2}$ Constantiner School of \\ Education, Tel-Aviv University, Israel \\ ${ }^{\star}$ Corresponding author: Hila Gendler-Shalev, University of Haifa - Communication Sciences and Disorders \\ Abba Khoushy Ave 199, Haifa 3498838, Israel E-mail: hilags2@gmail.com
}

(Received 7 January 2020; revised 1 November 2020; accepted 5 February 2021; first published online 19 March 2021)

\begin{abstract}
This article presents data on lexical development of 881 Israeli Hebrew-speaking monolingual toddlers ages $1 ; 0$ to 2;0. A Web-based version of the Hebrew MacArthurBates Communicative Development Inventories (H-MB-CDI) was used for data collection. Growth curves for expressive vocabulary, receptive vocabulary, actions and gestures were characterized. Developmental trajectories of toddlers with various demographic characteristics, such as education, income, religiosity level, birth order of the child, and child-care arrangements were compared. Results show that the lexical growth curves for Hebrew are comparable to those reported for other languages. Sex, birth order, and child-care arrangements were found to influence the size of lexicons. It is recommended that the trajectories presented here be used as norms for lexical growth among typical Hebrew-speaking toddlers in the second year of life.
\end{abstract}

\section{Introduction}

Lexical development trajectories are important for comparing the lexical levels of children who acquire the same language and for cross-linguistic comparisons. One of the most commonly used instruments for assessing early lexical development is the MacArthur-Bates Communicative Development Inventories (MB-CDI), which was initially constructed for American English-speaking children (Fenson et al., 1994; Frank, Braginsky, Yurovsky \& Marchman, in press). This instrument relies on parents' report about the words used by their children in closed lists of items. Throughout the last three decades, the MB-CDI lists have been adapted to more than 60 languages (Frank, Braginsky, Yurovsky \& Marchman, 2017) and were found to be valid and reliable for collecting data on the development of toddlers' lexicons (for an overview, see Fenson et al., 2007). 
This paper presents a cross-sectional, web-based study of the Hebrew MB-CDI words and gestures (WG) version. This version was adapted to Hebrew in 2005 (Gendler-Shalev). For the first study, data from a sample of 118 participants were collected with pencil and paper questionnaires and coded manually. The 2005 Hebrew adaptation version was found to be reliable for assessing the lexicon size of Hebrew-speaking toddlers ages $1 ; 0$ to $2 ; 0$. The 2005 sample was not large enough to calculate norms for Hebrew or to look for associations with sex, childcare or socio-cultural factors with lexicon size.

The size of toddlers' lexicons varies widely, as well as the rate of vocabulary growth in the early phases of speech production (Fenson et al., 1994). Therefore, to generate lexical trajectories that subsequently can be used as norms for Hebrew, data must be collected from a large, heterogeneous sample (Bates, Marchman, Thal, Fenson, Dale, Reznick, Reilly \& Hartung, 1994). In a society with high rates of Internet use, it is more efficient and cost effective to use a web-based MB-CDI questionnaire than traditional paper questionnaires (Kristoffersen, Simonsen, Bleses, Wehberg, Jørgensen, Eiesland \& Henriksen, 2013). Therefore, in the present study, the Hebrew MB-CDI was compiled in an electronic format and then distributed via the Internet.

In addition to mapping developmental curves, we explored the lexical development of Hebrew-speaking toddlers with varied personal and socio-cultural backgrounds. Studies performed in many languages reported that girls had larger expressive vocabularies and used more gestures than did boys (Eriksson, Marschik, Tulviste, Almgren, Pereira, Wehberg, Marjanovič-Umek, Gayraud, Kovačevič \& Gallego, 2012), first-born children were found to have larger expressive vocabularies than later-born children (Fenson et al., 1994; Urm \& Tulviste, 2016), and children from families with higher socioeconomic status (SES) had larger expressive vocabularies than did those from families with lower SES (Fernald \& Marchman, 2012; Hoff \& Ribot, 2015). The lexical development of children in various child-care arrangements has also been tested in different countries. Some showed an advantage for children spending less time in day-care nurseries (Urm \& Tulviste, 2016), while others showed no differences in the rate of lexical growth according to child-care arrangements (NICHD Early Child Care Research Network, 2002).

Comparing Hebrew lexical trajectories to other languages is especially interesting due to the unique characteristics of the Hebrew language and cultural topography of Israeli society. Hebrew is a Semitic language with rich inflectional non-concatenative morphology of consonantal "roots" and melodic "templates" (Kastner, 2019). The root often carries the core meaning of the word and the templates convey notions such as lexical category and verb transitivity (Maital, Dromi, Sagi \& Bornstein, 2000; Novogrodsky \& Kreiser, 2015). These major characteristics were considered when constructing the list of items in the H-MB-CDI, as well as in the instructions for parents on how to complete the questionnaires (Gendler-Shalev, 2005; 2019).

The socio-cultural context in Israel is characterized by a population with diverse political, religious and cultural beliefs. This diversity originates from a high rate of ongoing immigration to Israel from over 100 countries (Ziv, Zakai-Mashiach, Al-Yagon \& Dromi, 2014). Despite this heterogeneity, some characteristics are common to Israeli families which are signified by strong relationships within the nuclear family and close ties to the extended family (Hofstede, 2001). Israeli society is also characterized by values of individualism, self-actualization, free choice and freedom of expression, along with the values of loyalty and commitment to the state, and a strong sense of collectivist duty (Ziv et al., 2014). The child-rearing practices of 
Israeli parents are guided by beliefs that emphasize the importance of social competency, autonomy, and leadership (Rosenthal \& Roer-Strier, 2001). In terms of parenting practices, both mothers and fathers usually work in demanding jobs. Working mothers or fathers are entitled to a paid maternity leave of 15 weeks, and additional unpaid leave of 11 weeks. The parents decide who will take the leave and remain home with the baby (Bowers \& Fuchs, 2016). In the first year or two of life, some babies and toddlers of working parents are cared for individually by their grandparents or a nanny. Others are attended by a caregiver in small groups of 2-5 children or are placed in a day care center in which up to 35 children are supervised by 6-8 adult paraprofessional caregivers (Sagi, Koren-Karie, Gini, Ziv \& Joels, 2002). In Israel government-funded Well Baby clinics provide every child with immunizations, developmental follow-up, and parental guidance (Polak, Constantini, Verbov, Edelstein, Hasson, Lahmi, Cohen, Maoz, Daoud, Bentov, Aharony \& Stein-Zamir, 2015).

The objective of the current study was to measure the size of the receptive vocabulary, expressive vocabulary and actions and gestures used by a large sample of Israeli toddlers in their second year of life. Lexical growth curves of toddlers from different backgrounds were compared, examining sex, birth order, child-care arrangements and socio-economic status. Due to the unique characteristics of the Hebrew language and the diverse nature of Israeli society, findings from this study offer another perspective on universal versus language-specific developmental trends as reflected in vocabulary growth.

\section{Method}

\section{Participants}

Hebrew-speaking parents of 1,555 toddlers between the ages of 1;0 and 2;0 completed the Hebrew Web MB-CDI WG questionnaire and a background questionnaire (Gendler-Shalev, 2019). Among this sample, only 881 participants (417 girls, 464 boys) met the following study recruitment criteria: (a) the child was not treated for an ear infection more than once in the last three months; (b) Hebrew is the primary language the baby hears for at least ten hours a day; and (c) parents were not worried about the rate of the child's development. Table 1 shows the distribution of participants by age and sex. As can be seen the age groups ranged in size from 43 to 90 children. There were slightly more boys than girls in the sample.

Table 2 shows the distribution of the participants with reference to the background characteristics of education, income, religiosity level, birth order of the child, child-care arrangement. When the study sample is compared with the data reported in 2014 by the Israeli Central Bureau of Statistics (CBS), an overrepresentation of educated, high-income, non-religious parents characterizes the current sample. This finding corroborates with reported findings for MB-CDI investigations in other countries and in other languages and is inherent in the method of data collection that is not always accessible to participants in certain social subgroups (Frank et al., in press).

\section{The Hebrew Web MB-CDI WG questionnaire}

The MB-CDI WG form was adapted to Hebrew according to the format of the original English MB-CDI WG questionnaire. The Hebrew MB-CDI WG questionnaire consists of a list of 428 words in 18 semantic and grammatical categories (see Table 3 ). The words in each category are in alphabetical order. The parents were asked to mark the 
Table 1. Distribution of participants by sex and age in months

\begin{tabular}{lccc}
\hline Age (months) & Boys & Girls & Total \\
\hline 12 & 22 & 31 & 53 \\
\hline 13 & 38 & 22 & 60 \\
\hline 14 & 25 & 32 & 57 \\
\hline 15 & 37 & 25 & 62 \\
\hline 16 & 39 & 32 & 71 \\
\hline 17 & 37 & 44 & 81 \\
\hline 18 & 39 & 36 & 75 \\
\hline 19 & 55 & 35 & 90 \\
\hline 20 & 45 & 45 & 90 \\
\hline 21 & 46 & 44 & 90 \\
\hline 22 & 32 & 29 & 61 \\
\hline 23 & 23 & 20 & 43 \\
\hline 24 & 26 & 22 & 48 \\
\hline Total & 464 & 417 & 881 \\
\hline
\end{tabular}

words that the child "understands" and the words that the child "says and understands". Words that were not understood or said by the child were not marked. In the 2005 study, the questionnaire was found to be a reliable and a valid tool for early lexical development of Hebrew-speaking toddlers during the second year of life (GendlerShalev, 2005). Table 3 presents the number of different lexical items in Hebrew that appear in each category of the H-MB-CDI.

The second part of the questionnaire consists of a list of 70 actions and gestures in five categories (see Table 4). Parents were asked to mark the actions and gestures that the child produces.

Parents were instructed to mark a word even if it contained mis-articulations or childish phonological processes. Our definition of a word follows earlier MB-CDI studies in which words were defined according to their form and content in the target language (Fenson et al., 1994). For verbs, we instructed parents to avoid reference to inflections that proliferate in modern Hebrew and to refer to the content of the words for action. Parents were asked to mark the infinitive form of the term that appeared in the questionnaire even if the child says it in an inflected form (e.g., to mark 'to run' 'laruts' even if their child used plural 'ratsim' or first person, singular form 'ratsti'). Parents were instructed to differentiate between the words that the child ONLY UNDERSTANDS and the words that the child UNDERSTANDS AND SAYS and to mark the correct option for each lexical item.

\section{The Background Questionnaire}

The first part of the questionnaire consisted of 12 multiple-choice questions about the child and his or her development. The following topics were included in this section: 
Table 2. Distribution of participants according to their background characteristics in the Israeli MB-CDI study and the general Israeli population

\begin{tabular}{|c|c|c|c|}
\hline Characteristic & $N=881$ & $\%$ (of study) & $\%$ of population** \\
\hline \multicolumn{4}{|l|}{ Primary caregiver's education* } \\
\hline High school & 51 & 5.8 & 30 \\
\hline Vocational & 84 & 9.5 & 17 \\
\hline Academic & 734 & 83.3 & 48 \\
\hline Missing data & 12 & 1.4 & \\
\hline \multicolumn{4}{|c|}{ Secondary caregiver's education* } \\
\hline Elementary & 5 & 0.6 & 16 \\
\hline High school & 106 & 12 & 30 \\
\hline Vocational & 107 & 12.1 & 16 \\
\hline Academic & 614 & 69.7 & 38 \\
\hline Not relevant & 37 & 4.2 & \\
\hline Missing data & 12 & 1.4 & \\
\hline \multicolumn{4}{|l|}{ Income } \\
\hline Lower than average & 137 & 15.6 & 31 \\
\hline Average & 257 & 29.2 & 30 \\
\hline Higher than average & 459 & 52.1 & 39 \\
\hline Missing data & 28 & 3.1 & \\
\hline \multicolumn{4}{|l|}{ Religious group } \\
\hline Secular (non-religious) & 729 & 61.9 & 36 \\
\hline Traditional & 239 & 13.1 & 29 \\
\hline Religious & 154 & 13.1 & 14 \\
\hline Orthodox & 45 & 3.8 & 21 \\
\hline Missing data & 10 & 0.8 & \\
\hline \multicolumn{4}{|l|}{ Birth order } \\
\hline First born & 528 & 59.9 & \\
\hline Second born & 193 & 21.9 & \\
\hline Third born & 109 & 12.4 & \\
\hline Fourth born & 31 & 3.5 & \\
\hline Fifth or later born & 9 & 1 & \\
\hline Other/missing data & 11 & 1.3 & \\
\hline \multicolumn{4}{|l|}{ Child-care arrangement } \\
\hline Parent, at home & 102 & 11.6 & \\
\hline Grandparent (or other family) & 24 & 2.7 & \\
\hline
\end{tabular}


Table 2. (Continued.)

\begin{tabular}{lccc}
\hline Characteristic & $\mathrm{N}=881$ & \% (of study) & \% of population** \\
\hline Nanny & 31 & 3.5 & 8.7 \\
\hline Small group-care (up to 5 children) & 77 & 55.1 \\
\hline Private day-care (6-25 children) & 485 & 17.9 \\
\hline Nursery (more than 20 children) & 158 & 0.5 \\
\hline Missing data & 4 &
\end{tabular}

* in the current sample $85 \%$ of the primary caregivers were mothers and $15 \%$ of the primary caregivers were fathers. ${ }^{\star *}$ According to the Israeli Central Bureau of Statistics (2014) in the Hebrew-speaking population. Education of parents is reported separately for mothers and for fathers.

Table 3. The Hebrew MB-CDI WG word list categories

\begin{tabular}{lc}
\hline Category & Number of words \\
\hline Sound Effects and Animal Sounds & 14 \\
\hline Animal Names (Real of Toy) & 39 \\
\hline Vehicles (Real or Toy) & 12 \\
\hline Toys & 13 \\
\hline Food and Drink & 47 \\
\hline Clothing & 22 \\
\hline Body Parts & 19 \\
\hline Furniture and Rooms & 24 \\
\hline Small Household Items & 37 \\
\hline Outside Things and Places to Go & 29 \\
\hline People & 11 \\
\hline Games and Routines & 22 \\
\hline Action Words & 65 \\
\hline Descriptive Words & 37 \\
\hline Words About Time & 11 \\
\hline Pronouns & 8 \\
\hline Question Words & 9 \\
\hline Prepositions and Location & 9 \\
\hline Total & 428 \\
\hline
\end{tabular}

birth-order, pregnancy duration, birth weight, age when motor milestones were achieved, details of the child-care arrangements, and information on the languages spoken in the home. The second part of the questionnaire consisted of 11 questions about the parents' education, profession and SES of the family. The final section dealt with the religious group, marital status, employment status, and monthly income of the family. 
Table 4. Hebrew MB-CDI WG actions and gestures list

\begin{tabular}{lc}
\hline Category & Number of items \\
\hline First Communicative Gestures & 15 \\
\hline Games & 10 \\
\hline Actions with Objects or Toys & 16 \\
\hline Pretending to be a Parent & 21 \\
\hline Pretending with Objects & 8 \\
\hline Total & 70 \\
\hline
\end{tabular}

\section{Adaptation of the Hebrew MB-CDI to a Web Format}

The Hebrew MB-CDI and the background questionnaires were adapted to a web format. The computerization of the questionnaires followed the model of the Norwegian web MB-CDI (Kristoffersen et al., 2013). The web format of the questionnaire was built in HTML, PHP, and CSS programming languages using Zend software. The data were stored in the MySQL database management program on a standard Linux server at the University of South Denmark.

The questionnaires were embedded in a website that was built especially to collect data from a large Israeli sample (www.firstwords.co.il-in Hebrew). The website presented scientific information about early lexical development, as well as the goals of the current study. There was also a link to the official MB-CDI site (http://mb-cdi. stanford.edu/) where parents could find information about the adaptations to other languages and other studies that used the questionnaire. At the top of the home page of the site, there was a 'frequently asked questions' button, which provided information about the study, as well as a contact button for direct email communication with the researchers. The site encouraged parents to participate in the study by filling out the questionnaire and providing information about their children's vocabularies.

Parents who were willing to fill in the questionnaire clicked a button that directed them to a consent form approved by the Tel Aviv University Ethics Committee. Parents were directed to the next page of instructions on how to fill out the questionnaire only after selecting the approval box on the consent form. The instructions were colorful and included examples.

The landing page of the questionnaire had three fields for the parent to fill in: child's date of birth, parent's email address, and the child's name or nickname in case of twins. The first two fields were mandatory to get to the next page of the questionnaire. If the child's age was not within the age-range of 12- to 24 months, access to the questionnaire was automatically denied. After filling in the mandatory fields, an email was sent with an automatically generated password. The parent could start filling out the questionnaire after entering it. The web questionnaire consisted of ten pages, with a 'continue' button at the bottom of each page. Clicking this button saved the parents' answers temporarily, if they wished to take breaks and return to the questionnaire later. Parents could go back to the pages they had already filled out, if they had not clicked the 'Finish' button that appeared at the end of the questionnaire. The age of the child was calculated according to the time the parents finished filling out the questionnaire. The background questionnaire appeared at the end of the MB-CDI questionnaire. 


\section{Procedure}

The web Hebrew MB-CDI was distributed by intense marketing, such as creating a brand name and a logo for the 'First Words Project'. Flyers were designed and distributed to parents in shopping centers, parks, and child entertainment centers. The project was disseminated through social and other media, such as internet-based news magazines, as well as radio and television talk shows. In order to reach diverse SES populations, recruiting efforts took place in parenting-guidance centers in low-SES neighborhoods. Para-health professionals, doctors, nurses, teachers, and university students were recruited at professional conferences to advocate for the project. The web questionnaire was accessible by any device that had internet connection: personal computers, tablets, and smartphones.

\section{Results}

\section{General growth curves for word production, word comprehension, actions and gestures}

The scores for each participant were calculated as the sum of items that were marked for each of the variables word production, word comprehension, and actions and gestures. The growth curves presented here show the $0.10,0.25,0.50,0.75$, and 0.90 quantile ranks of the scores by age in month for each variable (see Figures 1-3). Growth curves were fit using the Growth Charts Regression Quantiles function from the R package quantregGrowth (Muggeo, Sciandra, Tomasello \& Calvo, 2013), which fits non-crossing regression quantiles as a function of linear covariates and multiple smooth terms via B-splines with L1-norm difference penalties. This analysis is based on the $\mathrm{R}$ codes from the "wordbank" project (http://wordbank.stanford.edu/) used for MB-CDI norming in other languages (Frank et al., 2017).

The results show that with age, toddlers' expressive and receptive vocabularies, as well as use of gestures, increased and included more entries (see Figures 1-3). Large variability was found among the Hebrew-speaking toddlers in comprehension, in production and in gesture use in the age range of 1;0 to 2;0 years, as was reported for other languages (Frank et al, in press).

The results show that as age increased, the gap grew between toddlers ranked at the lowest and highest quantiles in terms of the number of words produced by each group. The gap between the number of words produced by toddlers in the 0.10 and the 0.90 quantiles at 12 months was 24 words, while the gap between the number of words produced by toddlers in the same quantiles at 24 months was 279 words (see Figure 1).

The number of words comprehended grew as children matured. The variability between same-age toddlers remained similar throughout the second year of life. The gap between the number of words comprehended by toddlers ranked at the bottom and top quantiles was similar across age groups: 150-200 words (see Figure 2).

The number of actions and gestures toddlers used increased with age, too. The variability in the number of actions and gestures used by same-age toddlers remained similar throughout the second year of life. A similar gap of 20-28 items was found between the top and bottom quantiles in the different age groups (see Figure 3).

The lexical growth curves show that as age increased, children had larger expressive vocabularies, understood more words, and performed more actions and gestures. Similarly, the gap between the number of different words in the expressive vocabulary of toddlers in different quantiles was not stable and it became more salient with age. The gap remained stable in comprehension and in the generation of gestures and actions. 
400

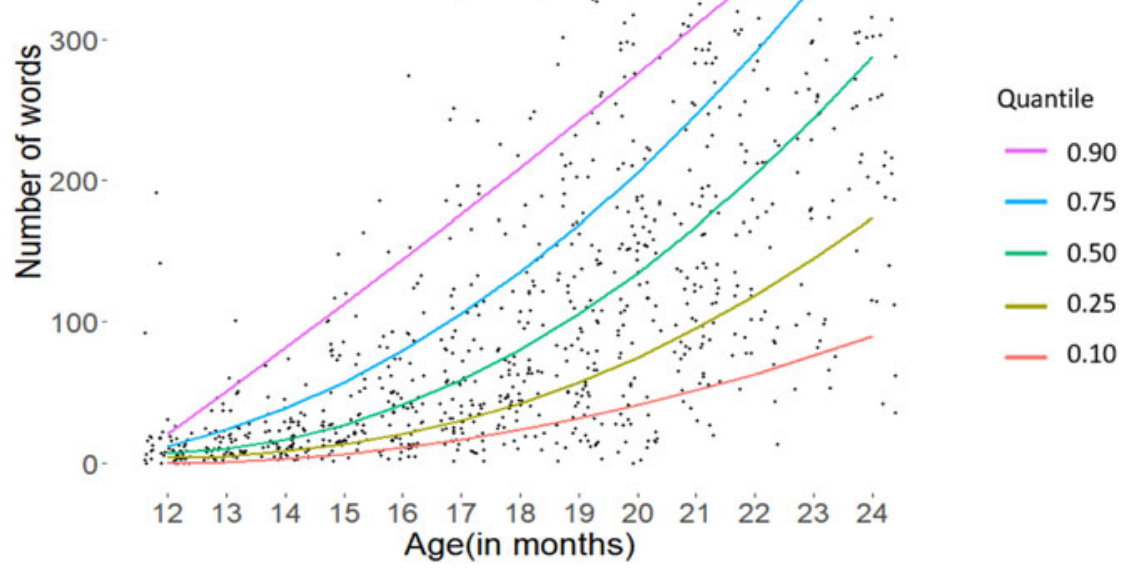

Figure 1. Quantiles for expressive vocabulary in Hebrew in the second year of life $(n=881)$

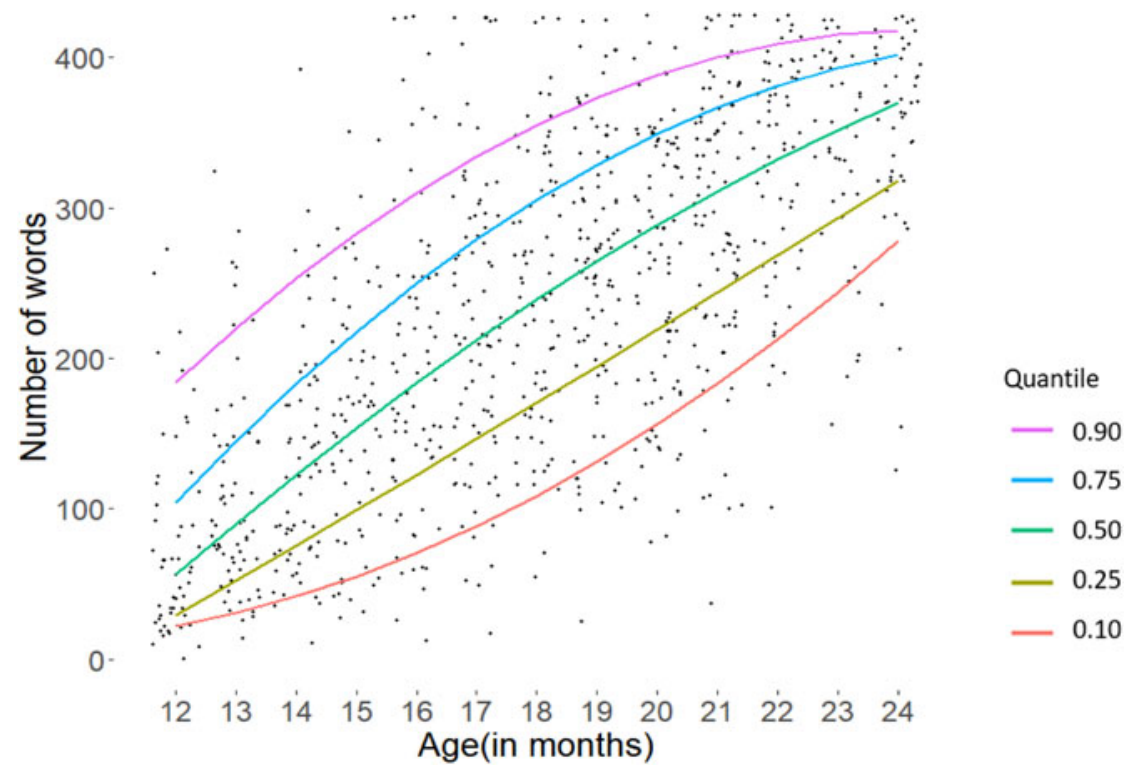

Figure 2. Quantiles for receptive vocabulary in Hebrew in the second year of life $(n=881)$

\section{Lexical development of toddlers with differing demographic backgrounds}

The effects of age and demographic background on expressive, receptive, and action and gesture vocabulary were examined using linear regression (a total of 3 analyses). For this purpose, categorical demographic variables were transformed into sets of dichotomous 


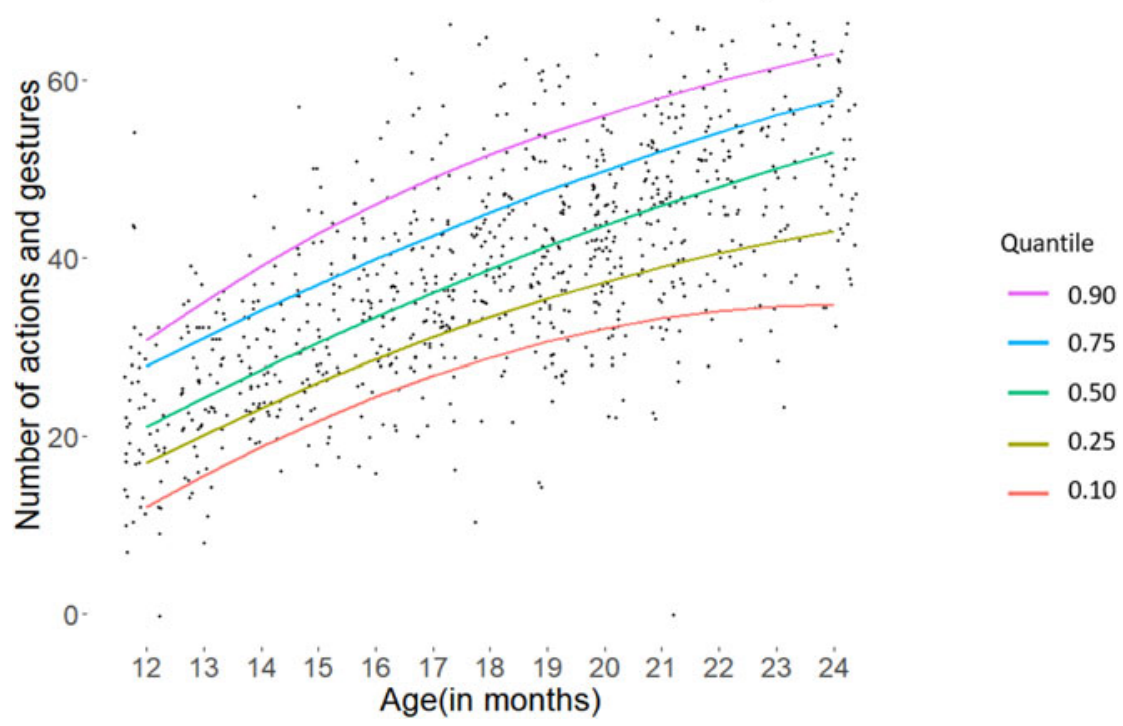

Figure 3. Quantiles for actions and gestures of Hebrew-speaking children in the second year of life $(n=881)$

"dummy" variables ( $\mathrm{n}-1$ variable for $\mathrm{n}$ categories, with the remaining category serving as the reference category). Children whose principal care takers were their parents, other relatives, or a nanny were grouped together to form a category referred to as "home care". Fourth and fifth born children, and children from orthodox families were omitted from the model due to the small number of participants with these values $(\mathrm{n}<50)$. Results are shown in Tables $5-7$.

\section{Expressive vocabulary}

Results showed that as toddlers become older, their expressive lexicons grew $(\mathrm{p}<.001)$. Among the background variables that were modeled, age contributed the largest proportion of the variance in expressive vocabulary size (squared semi-partial correlation $(\mathrm{SSPC})=0.434)$.

Girls had larger expressive vocabularies than boys did. These differences were statistically significant $(\mathrm{p}<.001)$. The unique contribution of sex to the variation in expressive vocabulary size was small $(\mathrm{SSPC}=0.012)$.

Results also showed that there were significant differences in the expressive vocabulary size of children according to birth order. First-born children were found to have larger expressive vocabularies than second- and third-born children $(\mathrm{p}<.001$, $\mathrm{SSPC}=0.012 ; \mathrm{p}<.01, \mathrm{SSPC}=0.005)$.

No significant differences were found in the expressive vocabulary of toddlers from different SES backgrounds. Caregiver's education, family income and family's religious group membership did not contribute to the variance in the expressive vocabulary of toddlers.

In addition, no significant differences were found in the expressive vocabulary size of toddlers based on child-care arrangements. The vocabulary size of toddlers who were cared for in their homes was similar to the expressive vocabulary size of toddlers who were raised in day care. 
Table 5. Linear regression of expressive vocabulary size on the demographic background variables

\begin{tabular}{|c|c|c|c|c|c|c|}
\hline $\begin{array}{l}\text { Variables } \\
\text { (reference category) }\end{array}$ & $B$ & SE B & Beta & $\mathrm{t}$ & $\mathrm{SSPC}^{\mathrm{a}}$ & $\mathrm{VIF}^{\mathrm{b}}$ \\
\hline Age & 22.117 & 0.837 & 0.688 & $26.415^{\star \star \star}$ & 0.434 & 1.090 \\
\hline \multicolumn{7}{|l|}{ Sex (girls) } \\
\hline Boys & -24.297 & 5.498 & -0.111 & $-4.419^{\star \star \star}$ & 0.012 & 1.012 \\
\hline \multicolumn{7}{|c|}{ Primary caregiver's education (academic) } \\
\hline High school & 6.509 & 12.182 & 0.014 & 0.534 & 0.0002 & 1.100 \\
\hline Vocational & -11.156 & 9.532 & -0.030 & -1.170 & 0.0008 & 1.068 \\
\hline \multicolumn{7}{|l|}{ Income (average) } \\
\hline Low & -1.768 & 8.513 & -0.006 & -0.208 & 0.0001 & 1.326 \\
\hline High & 0.974 & 6.478 & 0.004 & 0.150 & 0.0001 & 1.401 \\
\hline \multicolumn{7}{|c|}{ Religiosity (non-religious) } \\
\hline Traditional & -0.522 & 6.872 & -0.002 & -0.076 & 0.0001 & 1.097 \\
\hline Religious & -12.892 & 8.905 & -0.038 & -1.448 & 0.0001 & 1.112 \\
\hline \multicolumn{7}{|l|}{ Birth order (first) } \\
\hline Second & -29.693 & 6.854 & -0.113 & $-4.332^{\star \star \star}$ & 0.012 & 1.095 \\
\hline Third & -25.130 & 8.610 & -0.076 & $-2.919^{\star \star}$ & 0.005 & 1.084 \\
\hline \multicolumn{7}{|c|}{ Child-care arrangement (home one-on-one) } \\
\hline Nursery of 2-5 & 0.523 & 11.371 & 0.001 & 0.046 & 0.0001 & 1.401 \\
\hline Nursery of $6-20$ & -3.862 & 7.747 & -0.018 & -0.499 & 0.0001 & 1.990 \\
\hline Nursery of $21+$ & -4.595 & 9.524 & -0.482 & -0.482 & 0.0001 & 1.784 \\
\hline $\mathrm{R}^{2}$ & 0.480 & & & & & \\
\hline$F(d f)$ & $60.315(843)$ & & & & & \\
\hline
\end{tabular}

${ }^{a}$ Squared Semi-partial Correlation; ${ }^{b}$ Variance Inflation Factor; ${ }^{\star \star \star} p<.001,{ }^{\star \star} p<.01,{ }^{\star} p<.05$.

Multicollinearity was not detected among the different predictors that were modeled for expressive vocabulary size (VIF $<2$ for all variables).

\section{Receptive vocabulary}

Among the background variables modeled, age was the strongest predictor of receptive vocabulary size $(S S P C=0.46)$. The receptive vocabulary size increased with age $(\mathrm{p}<.001)$.

Results showed that birth order was a significant additional predictor for receptive vocabulary size. First-born toddlers had larger receptive vocabularies than did second-born and third-born toddlers $(\mathrm{p}<.001, \mathrm{SSPC}=0.011 ; \mathrm{p}<.01, \mathrm{SSPC}=0.007)$.

Toddlers who were raised individually by an adult in a home care arrangement had larger receptive vocabularies than toddlers who were raised in group-care nurseries of $2-5$ toddlers, $6-20$ toddlers or more than 21 toddlers $(\mathrm{p}<.001, \mathrm{SSPC}=0.008$; $\mathrm{p}<.001, \mathrm{SSPC}=0.007 ; \mathrm{p}<.01, \mathrm{SSPC}=0.004)$. 
Table 6. Linear regression of receptive vocabulary size on the demographic background variables

\begin{tabular}{|c|c|c|c|c|c|c|}
\hline $\begin{array}{l}\text { Variables } \\
\text { (reference category) }\end{array}$ & $B$ & SE B & Beta & $\mathrm{t}$ & $\mathrm{SSPC}^{\mathrm{a}}$ & $\mathrm{VIF}^{\mathrm{b}}$ \\
\hline Age & 23.696 & 0.863 & 0.708 & $27.455^{\star \star \star}$ & 0.460 & 1.090 \\
\hline \multicolumn{7}{|l|}{ Sex (girls) } \\
\hline Boys & -7.183 & 5.667 & -0.031 & -1.267 & 0.0001 & 1.012 \\
\hline \multicolumn{7}{|c|}{$\begin{array}{l}\text { Primary caregiver's } \\
\text { education (academic) }\end{array}$} \\
\hline High school & -3.005 & 12.557 & -0.006 & -0.239 & 0.0001 & 1.100 \\
\hline Vocational & -11.676 & 9.825 & -0.030 & -1.188 & 0.0008 & 1.068 \\
\hline \multicolumn{7}{|l|}{ Income (average) } \\
\hline Low & -0.960 & 8.775 & -0.003 & -0.109 & 0.0001 & 1.326 \\
\hline High & 1.836 & 6.678 & 0.008 & 0.275 & 0.0001 & 1.401 \\
\hline \multicolumn{7}{|c|}{ Religiosity (non-religious) } \\
\hline Traditional & 6.862 & 7.084 & 0.025 & 0.969 & 0.0005 & 1.097 \\
\hline Religious & -6.695 & 9.180 & -0.019 & -0.729 & 0.0003 & 1.112 \\
\hline \multicolumn{7}{|l|}{ Birth order (first) } \\
\hline Second & -30.046 & 7.065 & -0.110 & $-4.253^{\star \star \star}$ & 0.011 & 1.095 \\
\hline Third & -30.101 & 8.875 & -0.087 & $-3.391^{\star \star}$ & 0.007 & 1.084 \\
\hline \multicolumn{7}{|c|}{$\begin{array}{l}\text { Child-care arrangement } \\
\text { (home one-on-one) }\end{array}$} \\
\hline Nursery of 2-5 & -43.594 & 11.721 & -0.109 & $-3.719^{\star \star \star}$ & 0.008 & 1.401 \\
\hline Nursery of $6-20$ & -27.931 & 7.986 & -0.122 & $-3.498^{\star \star \star}$ & 0.007 & 1.990 \\
\hline Nursery of $21+$ & -26.876 & 9.817 & -0.090 & $-2.738^{\star \star}$ & 0.004 & 1.784 \\
\hline $\mathrm{R}^{2}$ & 0.492 & & & & & \\
\hline$F(d f)$ & $63.092(834)$ & $\star \star \star$ & & & & \\
\hline
\end{tabular}

${ }^{\mathrm{a}}$ Squared Semi Partial Correlation; ${ }^{\mathrm{b}}$ Variance Inflation Factor; ${ }^{\star \star \star} p<.001,{ }^{\star \star} p<.01$.

No significant differences were found in the receptive vocabulary size of girls and boys. In addition, no significant differences were found in the receptive vocabulary size of toddlers from different SES backgrounds. Caregiver's education, family income and family's religious group membership did not contribute to the variance in the receptive vocabulary size of toddlers.

Multicollinearity was not detected among the different predictors that were modeled for receptive vocabulary size ( $\mathrm{VIF}<2$ for all variables).

\section{Actions and gestures}

With age, toddlers also produced more actions and gestures $(\mathrm{p}<.001)$. Among the variables that were modeled, age was found to contribute the largest proportion of variance to actions and gestures $(\mathrm{SSPC}=0.426)$. 
Table 7. Linear regression of quantity of actions and gestures on the demographic background variables

\begin{tabular}{|c|c|c|c|c|c|c|}
\hline $\begin{array}{l}\text { Variables } \\
\text { (reference category) }\end{array}$ & $B$ & SE B & Beta & $\mathrm{t}$ & $\mathrm{SSPC}^{\mathrm{a}}$ & $\mathrm{VIF}^{\mathrm{b}}$ \\
\hline Age & 2.469 & 0.095 & 0.681 & $25.876^{\star \star \star}$ & 0.426 & 1.090 \\
\hline \multicolumn{7}{|l|}{ Sex (girls) } \\
\hline Boys & -4.088 & 0.626 & -.166 & $-6.526^{\star \star \star}$ & 0.027 & 1.012 \\
\hline \multicolumn{7}{|c|}{$\begin{array}{l}\text { Primary caregiver's } \\
\text { education (academic) }\end{array}$} \\
\hline High school & 0.698 & 1.388 & 0.013 & 0.503 & 0.0001 & 1.100 \\
\hline Vocational & -0.030 & 1.086 & -0.001 & -0.028 & 0.0001 & 1.068 \\
\hline \multicolumn{7}{|l|}{ Income (average) } \\
\hline Low & 0.311 & 0.970 & 0.009 & 0.321 & 0.0001 & 1.326 \\
\hline High & -0.527 & 0.738 & -0.021 & -0.714 & 0.0003 & 1.401 \\
\hline \multicolumn{7}{|c|}{ Religiosity (non-religious) } \\
\hline Traditional & 0.104 & 0.783 & 0.004 & 0.133 & 0.0001 & 1.097 \\
\hline Religious & -0.819 & 1.015 & -0.021 & -0.807 & 0.0004 & 1.112 \\
\hline \multicolumn{7}{|l|}{ Birth order (first) } \\
\hline Second & -1.556 & 0.781 & -0.053 & -1.993 & 0.003 & 1.095 \\
\hline Third & -1.053 & 0.981 & -0.028 & -1.073 & 0.0007 & 1.084 \\
\hline \multicolumn{7}{|c|}{$\begin{array}{l}\text { Child-care arrangement } \\
\text { (home one-on-one) }\end{array}$} \\
\hline Nursery of 2-5 & -3.881 & 1.296 & -0.089 & $-2.996^{\star \star}$ & 0.006 & 1.401 \\
\hline Nursery of 6-20 & -2.566 & 0.883 & -0.103 & $-2.907^{\star \star}$ & 0.005 & 1.990 \\
\hline Nursery of $21+$ & -2.734 & 1.085 & -0.085 & $-2.519^{\star}$ & 0.004 & 1.784 \\
\hline $\mathrm{R}^{2}$ & .470 & & & & & \\
\hline$F(d f)$ & $57.796(834)$ & $\star \star \star$ & & & & \\
\hline
\end{tabular}

${ }^{\mathrm{a}}$ Squared Semi Partial Correlation; ${ }^{b}$ Variance Inflation Factor; ${ }^{\star \star \star} p<.001,{ }^{\star \star} p<.01,{ }^{\star} p<.05$.

Girls were found to use more actions and gestures than boys. These differences were statistically significant $(\mathrm{p}<.001)$. The unique contribution of sex to the variation in expressive vocabulary size was small $(\mathrm{SSPC}=0.027)$.

Toddlers who were raised individually by an adult - a family member or a nanny used more actions and gestures than toddlers who were enrolled in group-care nurseries of $2-5$ toddlers, $6-20$ toddlers or more than 21 toddlers $(\mathrm{p}<.01, \mathrm{SSPC}=0.006 ; \mathrm{p}<.01$, $\mathrm{SSPC}=0.005 ; \mathrm{p}<.05, \mathrm{SSPC}=0.004)$.

No significant differences were found in the amount of actions and gestures used by toddlers from different SES backgrounds. Caregiver's education, family income and family's religious group membership did not contribute to the variance in receptive vocabulary size. In addition, birth order was not found to predict the amount of actions and gestures. Second- and third-born toddlers produced similar number of actions and gestures as did first-born toddlers. 
Multicollinearity was not detected among the different predictors that were modeled for actions and gestures (VIF $<2$ for all variables).

In summary, sex, birth order, and child-care arrangements were found to influence the size of lexicons. Girls had advantages over boys with respect to their expressive vocabulary size and in the number of actions and gestures used. Birth order differences in favor of first-born children were found for expressive and receptive vocabulary sizes. Toddlers who were raised in one-on-one homecare context had larger receptive vocabularies and used more actions and gestures than did children in group daycare arrangements.

\section{Discussion}

The Hebrew lexical growth curves reported in this study closely replicate those reported for other languages (Frank et al., in press). During the second year of life, children add new words to their expressive and receptive vocabularies and add more and more actions and gestures to their repertoires. In Hebrew, as reported in other languages, large individual variability was found in the lexical abilities of same-age toddlers. This variability is presumably related to differences in neurobiological maturation rates that impact the route individual children take while establishing their vocabularies. As Dromi (1987) and other investigators reported, the rate of word learning is not stable across time and it is possible to identify two phases in the one-word stage (see a review in Dromi, 2009). Individual differences among children, as well as consideration of the timing in the second year of life in which the data were reported justify the need to conduct large-scale studies of early language acquisition (Bates et al., 1994).

As reported with other languages (Eriksson et al., 2012; Simonsen, Kristoffersen, Bleses, Wehberg \& Jørgensen, 2014), Hebrew-speaking girls had relatively more words in their expressive lexicons and produced more actions and gestures than did age-matched boys. This relative advantage of girls was not identified in the receptive vocabulary, that was similar regardless of sex. There are several hypotheses to explain this finding. It might be that there are differences in the rate of physiological motor maturation between the two sexes that make girls more apt in terms of oral-motor planning than boys (Smith \& Zelaznik, 2004). The results are in agreement with this hypothesis showing that girls have an advantage in expressive vocabulary and in the execution of actions and gestures. Both abilities require motor skills and rely on motor skills that mature over time in the second year of life. No differences were found between boys and girls in receptive vocabulary size, an ability that does not require oral-motor skills and is associated with mental-cognitive skills (Dromi, 2018). Another assumption could be that parents expect girls to talk more and earlier. Therefore, they are more sensitive to the emergence of early words by their daughters (Wehberg, Vach, Bleses, Thomsen, Madsen \& Basbøll, 2008). These assumptions have not yet been studied directly and call for additional research.

In the present study, first-born children were more advanced in comprehension and in production of words in comparison with age-matched, later birth order toddlers. This finding is in accord with those from other languages (Fenson et al., 1994; Frank et al., in press; Urm \& Tulviste, 2016). The explanation we give to the important finding of an advantage in early lexical growth for children who are raised individually at home during the first two years of life is derived from the 
socio-pragmatic developmental theories that highlight the significance of parent-child dyadic interactions in early childhood (Adamson, 1995; Dromi, 2018, Kasari, Freeman \& Paparella, 2006). First-born children and those who are cared for in a one-on-one setting are involved more in interactions with adults, who facilitate the language acquisition process. We assume that toddlers who have more exposure to adult-child dyadic interactions benefit from more modeling circumstances and increased mutual attention. Hence, they can practice their communicative abilities more efficiently (Adamson, 1995).

Another possible explanation for the effect of child-care arrangement on receptive lexicon size could be related to the structure and content of the items appearing in the questionnaire. As argued previously (for example, Tardif, Gelman \& Xu, 1999), MB-CDI results may be biased by the types of words presented to the parents in the questionnaires. The form contains many words for objects that are used at home in everyday situations. Therefore, toddlers who attend day-care nurseries might have less exposure to these objects and, hence, are not exposed to household terms as much as children who are raised at home are. This explanation should be directly examined in future studies.

It should be noted that although significant differences were found between toddlers in terms of sex, birth-order, and child-care arrangements, the proportion of variance that the background variables explained was small. Therefore, when assessing toddlers' lexical development, professionals and researchers should take into consideration that only a small portion of the differences can be explained by the individual and background characteristics of the child.

As opposed to findings from other languages (Fernald \& Marchman, 2012; Hoff \& Ribot, 2015), in the present study, no differences emerged in the lexical abilities of toddlers whose parents reported different education or income levels. This finding supports the proposal that SES is not the only predictor of child-rearing behaviors and interactions among Israeli parents. This finding is consistent with results reported by Aram and Levin (2001) who found that the number of books and literacy-oriented toys of children at home predict the child's literacy level and not the family's SES.

Other researchers argued that the unique characteristics of the Israeli culture may explain the lack of effect of SES on developmental parameters. The close ties with the extended family may lead to adults interacting with the child (for example, the child's aunt or grandparents). The extended family may also enable availability of free child-care for families of any SES. These interactions may lead to more child-directed activities and adult-child interactions among families of diverse SES. In addition, the Israeli healthcare system which provides developmental follow-up and parental guidance to all families in Israel (Polak et al., 2015) may lead to fewer SES-related differences in the behaviors of parents belonging to different cultural groups (Hofstede, 2001; Sagi et al., 2002; Ziv et al., 2014).

\section{Conclusions}

Using a web-based data collection procedure enabled us to collect information from a large sample of typically-developing toddlers and to generate developmental growth curves for Hebrew-speaking children in the second year of life. These lexical development trajectories are much needed for scientific and clinical purposes. Scientists and speech-language pathologists are invited to use the trajectories presented in this paper as reference for the expected developmental curves for 
research and applied purposes. ${ }^{1}$ MB-CDI researchers of societies with high rates of internet adoption may consider using this method to efficiently target large samples in their own countries.

A limitation of this study is that it did not fully capture the diversity of Israeli society. As in other countries, in Israel highly-educated, high-income, non-religious parents were over-represented in the sample (Frank et al., in press). Future research should examine the lexical development trajectories of Hebrew-speaking groups who were under-represented in the present study and compare them to the trajectories reported here. Additional data needs to be collected in future studies and research on the lexical development of additional social groups (for example, bi-lingual families, children of newly coming immigrants), as well as clinical sub-groups of children with atypical development, which will extend our understanding of yet unanswered questions.

Acknowledgements. Data reported in this publication were collected by Hila Gendler-Shalev for her Ph.D. thesis at Tel Aviv University under the supervision of Prof. Esther Dromi.

Thanks are extended to the Herbert and Sharon Glaser Fund for awarding Gendler-Shalev with a grant and to Dr. Virginia A. Marchman for her thoughtful suggestions in the process of data analyses.

\section{References}

Adamson, L. B. (1995). Communication development during infancy. London: Routledge.

Aram, D., \& Levin, I. (2001). Mother-child joint writing in low SES: Sociocultural factors, maternal mediation, and emergent literacy. Cognitive Development, 16(3), 831-852.

Bates, E., Marchman, V. A., Thal, D., Fenson, L., Dale, P., Reznick, J. S., Reilly, J., \& Hartung, J. (1994). Developmental and stylistic variation in the composition of early vocabulary. Journal of Child Language, 21(1), 85-123.

Bowers, L., \& Fuchs, H. (2016). Women and parents in the labor market-Israel and the OECD. Policy Brief. Jerusalem: Taub Center for Social Policy Studies in Israel.

Dromi, E. (1987). Early lexical development. Cambridge: Cambridge University Press.

Dromi, E. (2009). Old data-New eyes: Theories of word meaning acquisition. In Mueller Gathercole, V. C. (Ed.), Routes to language: Studies in honor of Melissa Bowerman (pp. 39-59). New York, NY: Psychology Press, Taylor \& Francis.

Dromi, E. (2018). Autism- A journey toward understanding the spectrum. Niv. [In Hebrew].

Eriksson, M., Marschik, P. B., Tulviste, T., Almgren, M., Pereira, M. P., Wehberg, S., MarjanovičUmek, L., Gayraud, F., Kovačevič, M., \& Gallego, C. (2012). Differences between girls and boys in emerging language skills: Evidence from 10 language communities. British Journal of Developmental Psychology, 30(2), 326-343.

Fenson, L., Dale, P. S., Reznick, J. S., Bates, E., Thal, D. J., Pethick, S. J., ... \& Stiles, J. (1994). Variability in early communicative development. Monographs of the Society for Research in Child Development, i-185.

Fenson, L., Marchman, V.A., Thal, D.J., Dale, P.S., Reznick, S.J. \& Bates, E. (2007). MacArthur-Bates Communicative Development Inventories. Baltimore, MD: Paul H. Brookes Publishing Company.

Fernald, A., \& Marchman, V. A. (2012). Individual differences in lexical processing at 18 months predict vocabulary growth in typically developing and late-talking toddlers. Child Development, 83(1), 203-222.

Frank, M. C., Braginsky, M., Yurovsky, D., \& Marchman, V. A. (2017). Wordbank: An open repository for developmental vocabulary data. Journal of Child Language, 44(3), 677-694.

Frank, M. C., Braginsky, M., Yurovsky, D., \& Marchman, V. A. (in press). Variability and Consistency in Early Language Learning: The Wordbank Project. Cambridge, MA: MIT Press.

Gendler-Shalev, H. (2005). The adaptation of HCDI-WG parent questionnaire to Hebrew. Unpublished MA thesis. Tel-Aviv University. [In Hebrew]

Gendler-Shalev, H. (2019). Early lexical development of Hebrew-speaking toddlers: an empirical study of a large national sample. $\mathrm{PhD}$ thesis. Tel-Aviv University. [In Hebrew].

${ }^{1}$ OSF: https://osf.io/vu2na/ 
Hoff, E., \& Ribot, K. M. (2015). Language development: Influence of socio-economic status. International Encyclopedia of the Social \& Behavioural Sciences, 13, 324- 328.

Hofstede, G. (2001). Culture's Consequences: Comparing Values, Behaviors, Institutions and Organizations Across Nations, 2nd ed., Sage, Thousand Oaks, CA.

Israeli Central Bureau of Statistics (2014).

Kasari, C., Freeman, S., \& Paparella, T. (2006). Joint attention and symbolic play in young children with autism: A randomized controlled intervention study. Journal of Child Psychology and Psychiatry, 47(6), 611-620.

Kastner, I. (2019). Templatic morphology as an emergent property. Natural Language \& Linguistic Theory, 37(2), 571-619.

Kristoffersen, K. E., Simonsen, H. G., Bleses, D., Wehberg, S., Jørgensen, R. N., Eiesland, E. A., \& Henriksen, L. Y. (2013). The use of the Internet in collecting CDI data-an example from Norway. Journal of Child Language, 40(3), 567-585.

Maital, S. L., Dromi, E., Sagi, A., \& Bornstein, M. H. (2000). The Hebrew Communicative Development Inventory: Language specific properties and cross-linguistic generalizations. Journal of Child Language, 27(1), 43-67.

Muggeo, V. M., Sciandra, M., Tomasello, A., \& Calvo, S. (2013). Estimating growth charts via nonparametric quantile regression: a practical framework with application in ecology. Environmental and Ecological Statistics, 20(4), 519-531.

NICHD Early Child Care Research Network (2002). Early child care and children's development prior to school entry: Results from the NICHD Study of Early Child Care. American Educational Research Journal, 39(1), 133-164.

Novogrodsky, R., \& Kreiser, V. (2015). What can errors tell us about specific language impairment deficits? Semantic and morphological cuing in a sentence completion task. Clinical Linguistics \& Phonetics, 29(11), 812-825.

Polak, R., Constantini, N. W., Verbov, G., Edelstein, N., Hasson, R., Lahmi, M., Cohen, R., Maoz, S., Daoud, N., Bentov, N., Aharony, H. S., \& Stein-Zamir, C (2015). Public Health Nurses Promoting Healthy Lifestyles (PHeeL-PHiNe): methodology and feasibility. The Journal of Ambulatory Care Management, 38(2), 164-177.

Rosenthal, M. K., \& Roer-Strier, D. (2001). Cultural differences in mothers' developmental goals and ethnotheories. International Journal of Psychology, 36(1), 20-31.

Sagi, A., Koren-Karie, N., Gini, M., Ziv, Y., \& Joels, T. (2002). Shedding further light on the effects of various types and quality of early child care on infant-mother attachment relationship: The Haifa study of early child care. Child Development, 73(4), 1166-1186.

Simonsen, H. G., Kristoffersen, K. E., Bleses, D., Wehberg, S., \& Jørgensen, R. N. (2014). The Norwegian communicative development inventories: Reliability, main developmental trends and gender differences. First Language, 34(1), 3-23.

Smith, A., \& Zelaznik, H. N. (2004). Development of functional synergies for speech motor coordination in childhood and adolescence. Developmental Psychobiology, 45(1), 22-33.

Tardif, T., Gelman, S. A., \& Xu, F. (1999). Putting the "noun bias" in context: A comparison of English and Mandarin. Child Development, 70(3), 620-635.

Urm, A., \& Tulviste, T. (2016). Sources of individual variation in Estonian toddlers' expressive vocabulary. First Language, 36(6), 580-600.

Wehberg, S., Vach, W., Bleses, D., Thomsen, P., Madsen, T. O., \& Basbøll, H. (2008). Girls talk about dolls and boys about cars? Analyses of group and individual variation in Danish children's first words. First Language, 28(1), 71-85.

Ziv, M., Zakai-Mashiach, M., Al-Yagon, M., \& Dromi, E. (2014). Universal and cultural processes in theory-of-mind development: Insights from Israeli preschool children. In Advances in Social Cognition Research (pp. 215-232).

Cite this article: Gendler-Shalev H, Dromi E (2022). The Hebrew Web Communicative Development Inventory (MB-CDI): Lexical Development Growth Curves. Journal of Child Language 49, 486-502. https://doi.org/10.1017/S0305000921000179 